\title{
Adolescence: The Developmental Theories from Granville Stanley Hall to Emerging Adulthood
}

\author{
Geon Ho Bahn \\ Department of Psychiatry, College of Medicine, Kyung Hee University, Seoul, Korea
}

\author{
청소년기: Granville Stanley Hall부터 Emerging Adulthood까지 \\ 반건호 \\ 경희대학교 의과대학/의학전문대학원 정신건강의학교실
}

\begin{abstract}
Adolescence is known as the transition stage between childhood and adulthood. Stanley Hall described the emotional turmoil during adolescence as 'storm and stress' with the biological changes of puberty. Establishing identity and achieving secondary separation and individuation are the main development tasks. The innovative development in the field of biology has enabled us to explain the imbalance between adolescents' emotion and thinking ability due to the difference in the speed of development of the brain in adolescence, rapid changes in the limbic circuitry, and relative slow progress of the prefrontal lobe circuit. The tremendous changes in social culture have changed the definition of the developmental stages and the developmental goals in adolescence. Teenagers in the 21st century prefer living in cyberspace to the real world, and digital communication is more convenient than speaking in language. While the theory of sexual development that Sigmund Freud was concerned about was based on sex as the unitary sense, people perceive sex and gender separately and can change biological sex through surgery according to the gender they prefer. The diversity of gender identity emerged as a new adolescent development task. The classical psychoanalytic development theory is linear, and stage-based. The socio-demographic changes cause responsibility as an adult to be delayed in the late 20s. As a result of the complex interaction studies of the brain, body and environment, a new developmental stage, and emerging adulthood, are being highlighted.

Psychoanalysis 2020;31(4):63-69
\end{abstract}

KEY WORDS: Adolescence · Emerging adulthood · Development $\cdot$ Gender $\cdot$ Cyberspace.

Received: April 30, 2020 Revised: September 20, 2020 Accepted: September 20, 2020

Address for correspondence: Geon Ho Bahn, MD, PhD

Department of Psychiatry, College of Medicine, Kyung Hee University, 26 Kyungheedae-ro, Dongdaemun-gu, Seoul 02447, Korea

Tel: +82-2-958-8556, Fax: +82-2-957-1997, E-mail: mompeian@khu.ac.kr

\section{서 론}

1904년 Granville Stanley Hall은 'Adolescence; its psychology and its relations to physiology, anthropology, sociology, sex, crime, religion, and education'을 출판하였다 (Hall 1904). 'Adolescence'라는 용어는 '자란다'는 의미의 라 틴어 'adolescere'에서 유래하였으며, 본격적으로 학문적 연 구 대상이 되기 시작한 것은 이 책의 출간 이후라고 볼 수 있 다(Kemp 1992). 이 책은 십여 년 이상 준비한 끝에 출간된 1,400 여 쪽이 넘는 역작이며, 청소년과 관련된 다양한 내용

This is an Open Access article distributed under the terms of the Creative Commons Attribution Non-Commercial License (https://creativecommons.org/licenses/by-nc/4.0) which permits unrestricted non-commercial use, distribution, and reproduction in any medium, provided the original work is properly cited.
을 기술하였다(Arnett와 Cravens 2006). Hall은 청소년기를 '질풍노도의 시기(the time of storm and stress)'라고 지칭하 였고, 현재까지 사람들의 뇌리에는 청소년기란 내적 갈등이 폭발하는 시기로 남아있다(Bahn 등 2015). 책에 실린 내용 중 오늘날 인정받지 못하거나 차이가 많이 나는 내용이 있 기도 하지만, 놀랄 만큼 정확하게 일치하는 내용도 있다 (Arnett와 Cravens 2006). 현대 이론과 크게 차이를 보이는 것은 다음과 같다. 첫째, 용불용설의 진화이론으로 현대 사 회에서는 전혀 받아들이지 않고 있다. 둘째, 성 발달에 대한 견해, 특히 자위에 대한 내용은 현대적 시각으로 볼 때 오히 려 기묘하기까지 하다. 그는 자위가 광학 경련(optical cramp) 부터 성장지연까지 각종 질병의 원인이므로, 성적 충동을 조 절하기 위해 억제와 치환의 복합 방법을 지지하였다. 성 발 달에 관한 Hall의 이론은 이 분야에서는 첫 사례였으나 프로 
이트의 정신성 발달 이론에 가려서 빛을 보지 못했다. 셋째, 개종(religious conversion)이 정상적이고 보편적이라는 것 이다(Arnett와 Cravens 2006). 개종은 청소년기 특징인 '질 풍노도'의 정상적인 결과로 간주되었고, 청소년 성장 과정 중 '자기중심성'에서 '이타주의'로 전환되는 기전을 설명한다고 여겼다(Kemp 1992). Hall이 주장한 개종이란 현실의 한계와 타인의 욕구에 대해 자기를 억제하는 심리적 과정이며, 이는 영적인 믿음을 끌어안는다는 현대적 종교와는 다른 개념이 다(Bahn 2015). 100년이 지난 오늘날까지 인정받는 내용 중 에는 청소년기의 높은 우울감 유병률, 범죄율이 최고조에 달 하는 시기, 높은 자극추구 경향, 미디어 영향에 대한 취약성, 또래 관계 특성, 생물학적 발달, 특히 뇌 발달 등이 있다.

미국 매사추세츠에서 농부의 아들로 태어난 Granville Stanley Hall(1846 1924)은 ‘아동 연구 운동'의 선구자이며, 1888년 대학원 중심의 클라크 대학(Clark University) 초대 총장으 로 부임하여 1920년 총장직을 사퇴할 때까지 이 대학을 심리 학 특성화 대학으로 육성하였다(White 1990). 심리학은 19세 기 후반까지도 철학, 생리학, 생물학에 뿌리를 둔 신생학문 이었고, Hall은 1878년 미국에서 처음으로 박사 학위를 받은 인물이다(Arnett와 Cravens 2006). 박사 과정을 마치고 독일 에서 2년여 추가 수련을 받았으며, 미국으로 돌아온 뒤 아동 발달을 연구하며 청소년기에도 관심을 갖게 되었다. 1892년 에는 미국심리학회(American Psychological Association)를 발족하였고, 초대 회장이 되었다. 그는 또한 정신분석을 미국 에 소개하고 파급시키기 위해 크게 기여하였다. 1909년 가을, 지그문트 프로이트와 칼 구스타프 융을 포함한 유럽의 정신 분석가들을 미국으로 초대하였고, 클라크 대학에서 정신분 석을 소개하는 특강을 주선하였다(Arnett와 Cravens 2006).

Hall이 청소년기를 지칭한 'storm and stress'라는 용어는 Friedlich von Klinger(1752 1831)의 희극 제목 'Sturm und Drang'이기도 하며, 1765년부터 1785년 사이에 독일에서 진 행된 계몽주의에서 낭만주의/고전주의 시대에 걸쳐 과도적 역할을 한 문학/연극 운동을 말한다(Kemp 1992). 거친 청년 의 열광과 파괴가 이 운동의 본질이며, 단기간 동안 지속되 었음에도 불구하고, 후대의 문학운동에 커다란 영향을 끼쳤 다. 청소년기에 감정적 소용돌이를 경험한다는 이론은 오늘 날 많은 학자는 물론 대중에게 각인되어 있다.

Hall이 다양한 분야에서 청소년기 관련 논의를 시작한 뒤 정신분석가들의 청소년기 관련 발달이론 연구가 활발해졌 으며, 생물학, 사회학 등 다양한 분야로 확산되었다. 최근에 는 디지털 문화의 폭발적 확산 등으로 인한 사회문화적 변 화가 청소년기 발달에 미치는 영향에 대한 논란이 커지고 있다. 임상 현장에서 청소년과 그 가족을 만나는 전문가들에
게 이러한 변화에 보조를 맞추는 데 도움을 주고자, 본고에 서는 Hall의 청소년기 연구 도입 이후 진행된 고전적 정신분 석적 발달이론을 간략히 정리하고, 청소년기와 성인기의 중 간 단계로 대두된 emerging adulthood 개념을 포함한 최근 청소년기 발달 관련 주제를 검토하였다.

\section{본 론}

\section{청소년기는 내적 격동의 시기인가?}

지그문트 프로이트는 정신성 발달단계이론에서 리비도 역동의 발달 단계를 발달이론의 초석으로 소개하였다(Gay 1998). 프로이트는 'Three essays on the theory of sexuality' 에서 사춘기와 청소년기는 위대한 시험대에 오르는 시기라 고 하였다(Gay 1998). 이 시기에 그들은 성적 정체성을 공고 히 하고, 오랜 세월 동안 지속되어 온 오이디푸스 콤플렉스 의 애착을 되살리며, 성적 만족의 달성을 위해 성기의 지배 권을 확립한다. 그렇다고 해서 성기에 성생활을 독점적으로 부여하지 않는다. 어린 시절의 성감대는 여전히 즐거움을 제 공하지만, 청소년기의 성적 쾌락은 사춘기와 함께 찾아오는 새로운 경험을 구성한다는 점에 주목할 필요가 있다고 하였 다(Gay 1998).

안나 프로이트(Freud 1958)는 청소년기를 논할 때 정상 과정보다 병적 특징을 기술하는 것이 더 쉽다고 할 정도로 정상 청소년기를 정의하기는 어렵지만, 정상 청소년기의 특 징으로 다음과 같은 두 가지 개념을 소개하였다. 첫째, 청소 년기는 근본적으로 평화로운 성장의 중단이며, 둘째, 청소년 기 동안 꾸준히 평정을 유지하는 것 자체가 비정상적이다. 안 나 프로이트(Freud 1958)는 청소년기에 방어기제를 사용한 결과, 병적 상태가 된다고 해서 이러한 결과를 악성이라고 여 기기보다는 방어기제가 과도하게 사용되었거나, 과하게 강 조되었거나, 또는 단독으로 사용되었기 때문일 수 있다고 보 았다. 청소년이 예측불허의 일관성 없는 행동을 계속한다면 아이도 고통을 받겠지만, 안나 프로이트는 아이를 반드시 치 료할 필요는 없다고 하였다. 스스로 해결책을 찾을 수 있도록 시간을 주고, 대신 부모가 아이 문제에 잘 대처할 수 있도록 도 움을 주는 것이 적절하다고 하였다. 그러나 세월이 흐르면서 청소년기 격동은 과도하게 일반화된 결과라는 주장이 힘을 얻 게 되었다(Figure 1). Offer와 Schonert-Reichl(1992)은 과거 이십여 년간 발표된 청소년 관련 연구를 검토한 결과, 청소년 의 약 $80 \%$ 는 이 전환기를 꽤 잘 조절하며 지나게 되므로 모 든 청소년이 심한 정서적 격동을 경험하는 것은 아니라고 결 론지었다. 단, $20 \%$ 정도의 청소년은 자기들에게 필요한 만큼 도움을 받고 있지 못하다는 점을 강조하였다. 


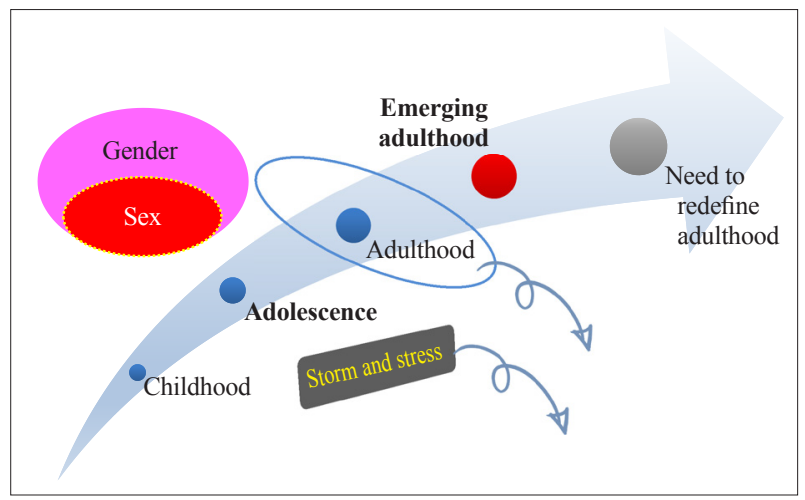

Figure 1. Adolescence as a transition from childhood to emerging adulthood.

\section{청소년기의 단계 및 발달과제}

원시 시대나 산업혁명 이전까지만 해도 성적 위치가 결정 되는 대로 아동기에서 성인기로 곧바로 진행이 가능하였으 나, 사회가 산업화되고 도제 제도와 교육 제도의 도입으로 사춘기가 점차 길어지고 있다(Muuss 1970). 청소년기의 시 작을 사춘기 성호르몬에 의한 신체 변화가 일어나는 때로 하는 데는 이의가 없으나, 청소년기와 성인기의 경계를 정하 는 일은 쉽지 않다. 투표, 혼인, 군 입대, 재산권 행사, 주류 소비, 범죄행위에 대한 처벌 여부 등과 같이 청소년과 성인 의 경계를 구분하도록 규정한 나이가 국가와 법령에 따라 다양하다(Bahn 2015). 청소년보호법에서는 19세 미만, 청소 년지원법은 24세, 유엔 산하의 유니세프에서는 19세로 정하 고 있다(Bahn 2015). Colarusso(1992)는 청소년기를 청소년 직전 단계(11 13세), 초기 청소년기(13 15세), 중기(15 17 세), 후기(17 19세)로 나누어 설명하였다.

청소년기의 주요 발달과제는 첫째, 부모로부터의 신체적, 심리적으로 떨어져 나가기이다. 이때 청소년들은 자기 정체 성 형성을 위해 부모의 가치 체계를 전면적으로 부정하거나 거리를 두려 한다. 하지만 한편으로는 부모의 가치체계 안에 머물며 그것을 자신의 자아 이상으로 받아들여 행동화하고 성취하려는 욕망을 갖게 되는 양가적 갈등의 시기이며, 이차 분리-개별화 단계이다(Blos 1967). 초기 청소년기에는 인지 적으로나 뇌발달 단계상 생각보다 감정에 따라 행동을 결정 하기 때문에 실수하는 경향이 많고(Silvers 등 2017), 부모보 다 친구가 중요해지는 시기이다. 때문에 부모는(부모 생각 에) 나쁜 친구들과 어울리며 자신들을 떠나려는 자녀를 이 해하지 못하고, 그 결과 건강한 2 차 분리개별화를 방해하게 된다. 부모와 청소년 자녀의 성공적인 분리 개별화를 위해서 는 양자가 모두 참여하는 동시적 개별화(synchronized separation-individuation)가 필요하다(Moon과 Bahn 2016). 둘 째, 이성관계의 확립이다. 초기 청소년기에 성적으로 성숙해
지는 몸을 받아들이는 것은 이 단계의 주요 과제이다 $\left(\mathrm{Co}^{-}\right.$ larusso 1992). 중기 청소년기에는 다른 성을 향해 다가가는 것이 달성해야 할 과제이다. 대개 실제 접촉보다는 공상이나 자위를 통해 성적인 감정을 키워나간다. 후기 청소년기는 성 교를 포함한 적극적 성생활을 할 심리적 준비를 마치게 된 다. 셋째, 자아정체성의 확립이다. 청소년기는 성인이 되기 전 아동기의 마지막 단계이므로, 아동기 동안 진행된 동일시 외에 새로운 동일시가 추가되는 시기이다(Erikson 1968). 사 회성을 키우고 경쟁적 직업훈련에서 살아 남아야 하기 때문 에 유년기의 장난스러움과 젊음의 실험적 열정을 떼어내야 한다. 청소년기의 정체성은 앞으로의 삶, 즉 개별화 과정, 성 정체성, 성인세계에서의 위치에 결정적 영향을 미칠 수 있기 때문에 오히려 긴박함과 급박함이 동반된다(Colarusso 1992). 특히 성적 지향은 사춘기 때 고정되는 것이 아니지만 중기 청소년기, 후기 청소년기, 성인기 초기의 성적 경험에 영향을 받을 수 있는 가능성이 있다. 청소년기에는 개인의 정체성과 집단 정체성이 상호 영향을 미친다(Bahn 등 2017). 자기(self) 는 사회와 연결되어 있기 때문에 청소년은 소속감을 느끼고 싶어하며 어딘가 연결되어 있기를 희망한다. 그런 점에서 해 리 포터에 나오는 호그와트 마법학교의 분류 모자는 개인의 성향에 부합하는 집단 정체성을 확인해주는 도구이다.

임상적으로 치료자는 청소년기의 단계별 특성과 발달과 제를 이해함으로써 청소년이 보이는 문제행동이나 문제 출 현 시기를 해석하고 치료에 적용할 수 있을 것이다 $\left(\mathrm{Co}^{-}\right.$ larusso 1992). 중학생 시절에 해당하는 초기 청소년기는 아 동기나 후기 청소년기보다 더 적응이 힘들고 심리적 갈등이 큰 것으로 알려져 있으나, 실제 임상에서는 덜 주목받고 있 다(Jacobs 2000). 초기 청소년기 기억은 정도 차이는 있지만 평생 억압이 지속되는 한편, 성격형성, 특히 자기표상에 미 치는 영향은 상당하다. Jacobs(2000)는 네 가지 사례 보고를 통해 초기 청소년기가 성격발달에 미치는 영향이 개인에 따 라 장단기적으로 차이가 있음을 확인하였다. 1) 초경관련 갈 등이 수십 년이 지난 뒤 폐경기 동안 재현되는 사례, 2) 30세 의 매력적인 미혼 여성이 초기 청소년기 때 경험한 부정적 자기상에 뿌리를 둔 우울증을 호소함, 3) 머리 좋고 재주 많 은 여대생 사례에서는 10 대 초반의 미해결 갈등 때문에 절 도, 마약, 문란한 성행동을 보임, 4) 열한 살 때 갑자기 엄마 를 교통사고로 잃고 의젓하게 수년간 적응하던 남학생이 고 등학생이 되면서 아버지와의 관계를 힘들어하고 나이에 맞 지 않는 여성편력을 보이는 등 상실의 두려움을 드러낸 사 례. 중기 청소년기는 고등학생 시기에 해당하며 사춘기 변화 가 완성되고 인지적으로 성찰 능력이 발달하며, 친구 관계에 서도 맹목적 관계를 벗어나게 되고, 관심의 방향도 사회문제 
까지 확대된다. 초기 청소년기에 성적으로 성숙한 몸을 받아 들이고 나면 중기 청소년기 동안 자아 이상을 형성해 가면서 점차적으로 이성애로의 전환이 진행된다(Colarusso 1992). 청소년기에는 오이디푸스기의 대상들과의 정신내적 연결을 느슨하게 만들고, 비근친상간적 관계에서 사랑하는 느낌과 성적 느낌을 갖도록 하는 데 있다는 점에서 성인의 사랑과 차이가 있다. 청소년기 사랑은 동성애적 및 양성애적 성향을 해결하는 데 유익하다. 즉 소년, 소녀가 사랑에 빠지면 소녀 는 자신의 여성성과 사랑받음을 느끼는 한편, 자신의 남성적 호기심을 소년에게 투사하고 그를 통해 즐길 수 있다. 소년 도 마찬가지이다. 성행위가 남녀관계의 일부가 될 때 편안하 게 수동적 및 능동적 성향을 표현하고 서로 실험해 볼 수 있 다. 이러한 상호 동일시는 각각 다른 이와의 새로운 관계를 통해 가다듬어지고, 훗날 결혼을 하게 되면 양성애적 성향을 확실히 해결하고 부모로서의 정체성을 완성하게 된다 $\left(\mathrm{Co}^{-}\right.$ larusso 1992). 후기 청소년기는 고등학교 말기부터 대학생 초기 단계이며, 욕동과 성인으로서의 능력을 시험하고 숙달 하는 시기이며, 자기, 초자아, 자아 이상에 대한 감각을 수정 해 나가는 기간이다(Settlage와 Galenson 1976). 후기 청소 년기에 이어지는 초기 성인기는 성인으로서의 능력을 시험 하고 통합해가는 기간이다. 특히 여성의 경우 성인으로서의 정체성은 임신과 출산, 육아 경험에 의해 명료화되고 강화된 다. 오늘날 결혼 연령이 높아지고 임신 출산 연령이 높아지 다 보면 후기 청소년기에서 바로 성인기로 이어질 수 없고, 따라서 뒤에 설명하게 될 신생 성인기가 출현하게 되는 이 유가 된다.

\section{사춘기의 신경생물학적 측면}

청소년기 뇌 발달 연구 분야 중 정서 조절 관련 뇌 회로 연 구가 많은 관심을 모았다(Young 등 2019). 이는 불안 및 우 울과 연계되기 때문이다. 불안에 관여하는 두 영역은 편도와 전전두엽피질이다. 편도는 공포의 형성, 유지, 표현을 지원 하는 내측두엽 구조물이다. 복내측 전전두엽피질은 공포 표 현의 조절과 소거를 조절한다. 청소년기에 변연계 회로 변화 는 매우 빠르게 진행되고, 전전두엽 회로 발달은 비교적 서 서히 진행되면서 발달 속도의 불균형이 생겨나며, 그 결과 청소년은 이성적 판단보다 감정이 앞서게 된다. 실제로 청소 년기 정신장애 유병률은 주의력결핍과잉행동장애 같은 소아 기 발병 정신장애의 진단 유병률이 낮아지고 불안 및 우울장 애가 급격히 증가하는 특징을 보인다(Hwangbo 등 2016). 청 소년기를 거치는 동안 복내측 전전두엽피질-편도 연결망은 좌측 복외측 전전두엽피질과 편도의 조율을 촉진하여 감정조 절 기능을 향상시킨다(Silvers 등 2017). 이러한 연구 결과를
불안과 우울증의 인지행동치료 등에 활용할 수 있다(Young 등 2019).

\section{Sex와 gender}

초기 청소년기가 훗날 영향을 미치는 정도나 형태는 성별 에 따라 다를 수 있다(Jabocs 2000). 초경 나이가 점차 빨라 지는 것을 포함해서 여자 청소년들에게는 이 시기를 보내는 것이 남자 청소년들보다 더 어렵고 복잡하다(Bahn 등 2015). 생리, 유방 발달, 체형변화, 지방분포처럼 사춘기 여아들이 겪는 공통적 주제 외에도, 성정체성 수용관련 갈등, 또래 간 비교와 대결의식, 문화적으로 미의 이상형 기준 차이도 여자 아이들을 힘들게 만든다. Shulman(2017)의 연구는 친밀한 사랑의 대상관계에도 성에 따른 차이가 있다고 하였다. 남성 은 애정관계에서 어려움이 생기면 발을 빼고 공부나 직업 쪽으로 더 시간을 할애하게 된다. 여성은 덜 만족스럽다고 해도 가급적 연결이 지속되기를 원한다. 즉 남성은 단기적 관계, 여성은 장기적 관계를 선호한다. 남녀 모두 이 시기 동 안 진정한 친밀한 관계를 맺지 못하다면 우울감에 빠진다. 이는 이 시기 발달에서 문화적 환경 척도가 자기 가치감과 감정 상태에 지대한 영향을 미침을 보여준다.

이러한 성별 차이는 생물학적 섹스와 젠더를 단일 개념으 로 전제한 것이다. 17 18세기까지는 남녀 신체의 해부생리 학적 구조는 태아기에 동질의 생식기관, 즉 양성의 특징을 지닌 단일 신체 기관이 성장 과정에서 각각 다르게 자리잡은 것으로 보았다(Laqueur 1990). 18세기 말에 접어들면서 '두 개의 성 체계(two-sex system)' 이론이 발달하기 시작하였다 (Nye 2010). 20세기 초 성호르몬 연구와 이어진 유전학 연구 를 통해 단일 개념의 성(sex as unitary sense)과 젠더의 차이 가 불분명해지기 시작했고, 학문적으로 구체화되기 시작한 것은 John Money(1921 2006)가 기여한 바가 크다(Nye 2010). 그는 1950 60년대 자웅동체(hermaphrodites) 연구를 진행하면서 수술로 생물학적 성을 바꿀 수 있다고 보고하였 다(Money 1995). 젠더의 정의는 아래와 같이 바뀌었다(Money와 Ehrhardt 1972). 첫째, 하나의 남성형 또는 여성형이라기 보다는 더 포괄적인 개념, 둘째, 단지 남자나 여자 같은 상태뿐 아니라, 한 인간으로서의 인식, 사회적 책무, 법적 결정과 관 련된 개념, 셋째, 생식기에 근거할 뿐 아니라, 생식기의 차이 를 넘어서 신체적 그리고 행동상 기준에 근거한 개념. 이후 성역할(sex role, gender role), 성정체성(gender identity)과 같은 용어를 소개하였다. 존스 홉킨스 대학의 심리학 교수였 던 Money는 1966년 동 대학의 성정체성클리닉 설립에 일조 하였고, 이후 이 클리닉에서는 최초의 성전환술을 시작한 이 후 수천 건의 성전환수술을 시행하고 있다(Agana 등 2019). 
생물학적 발달 외에도 페미니스트 운동과 정신장애 진단 기준 변화와 더불어 gender는 sex와 동등한 의미와 기능을 갖게 되었다(Figure 1) (Nye 2010). 과거에는 선천적 성이 sex 였으며, 문화적 성이 gender였으나, 오늘날 gender가 남성과 여성의 차이를 정의하고 sex를 대체하는 추세이다(Nye 2010). 그러다 보니 성 관련된 주제 중 매우 예민하고 다루기 힘든 내용은 성정체성이다. 현재 Diagnostic and Statistical Manual of Mental Disorders, 5th ed(DSM-5; American Psychiatric Association 2013)에 남아 있는 성정체성 관련 장애는 성정체성 불쾌증(gender dysphoria) 뿐이지만 성전환자 또 는 성전환 예정인 청소년의 성정체성 불쾌증에 대해 정신치 료가 필수는 아니라고 주장하기도 한다(Nealy 2017). 성정 체성 문제가 더 이상 정신병리에 포함되지 않기 때문이며, 가족과 친구들의 격려와 수용만으로 변화의 시기를 견딜 수 있다고 한다. 치료 필요성보다는 그들이 겪는 혼란, 두려움, 격리감 등에 대한 이해를 돕고, 성정체성을 밝히고 나서 살 아가는 방법이나 예상되는 문제에 대한 지도가 필요할 수 있다. 때로 성전환 청소년의 가족에게 도움이 필요할 수도 있다. 하지만 성정체성 문제는 여전히 심각한 정신병리를 유 발한다는 주장이 계속되고 있으며, 성전환자 중 특히 남성과 최종 성 미결정자(nonbinary) 중 출생 시 남성인 경우는 다 른 집단에 비해 우울과 자살사고(시도)가 더 심하다는 주장 이 있다(Price-Feeney 등 2020). 분석가에 따라 성정체성 문 제의 치료 방향과 개념에 대해 의견 차이가 생길 수 있다. Gilmore(1995)는 '실제' 또는 '올바른 성정체성'은 생물학적 으로 결정된다는 입장이다. Gilmore가 7년간 분석한 입양아 동의 성정체성 불쾌증은 신체 문제가 아닌 입양, 분리불안, 입양모의 불임 등과 관련된 정신적 문제였으며, 분석 종결 시 아동은 자신의 생물학적 성을 선택했다. Suchet(2011)는 여성에서 남성으로 전환한 사례를 소개하였다. 분석가와 피 분석가 모두 성전환이 적절한 해결책임을 받아들였다.

\section{사이버여행자 세대}

청소년은 아동기의 상실과 이상화된 부모상 상실 과정에서 자기애의 퇴행을 경험하고 극복하면서 발달한다(Tylim 2017). 이러한 발달은 오랜 시간을 필요로 한다. 그러나 사이버 공 간에서 생활하는 청소년은 사이버여행자(cybernaut)가 되어 사이버소통(texting, whatsapp, Instagram, twitter, email 등) 을 통해 짤막한 농담이나 이모티콘, 또는 몇몇 단어만으로 순식간에 주관을 형성하고 바꾸어 나간다. 이렇듯 대인관계 형태는 디지털로 표현되고 순식간에 전달된다. 사이버 공간 을 차지하고 있는 가장 많은 내용 중 하나는 성 관련물이다 (Saleh 등 2014). 인터넷은 소위 AAA 엔진이다. 즉 접근성 (accessibility), 감당할만한 가격(affordability), 익명성(anonymity) 등, 나이, 지역, 언어, 시간 등을 초월한다. 정신성 발달 과정에서 부모와 사회의 역할이 필수적이었으나, 사이 버 공간에서 진행되는 성 관련물 노출에 부모가 관여하는 것이 거의 불가능하다. 특히 2019년 말부터 시작된 코로나 바이러스 확산 사태는 인터넷의 긍정적 및 부정적 영향을 폭발적으로 늘어나게 하고 있다. 수개월 이상 지속된 휴교 상태로 인해 소아청소년의 재택학습 기간이 길어지면서 과 도한 인터넷 사용이나 과도한 인터넷 게임 시간과 관련된 문제가 발생한다(King 등 2020; Király 등 2020). 심지어 코 로나 바이러스 홍보물을 가장한 음란물 동영상에 청소년은 물론 어린 소아들도 무차별적으로 노출되고 있다(MestreBach 등 2020).

\section{청소년기의 확장인가, 성인기 진입단계의 변화인가?}

정신분석의 시각은 기본적으로 직선적, 단계별 발달 이론 이다(Stambler 2017). 지그문트 프로이트는 이론 개발 당시 다윈의 진화론 영향을 받았고 덕분에 일직선상으로 발달한 다는 개념이 도입되고 굳어졌기 때문이다. 그러나 사회변화 와 더불어 청소년기가 길어지면서 정상과 병리에 대한 개념 과 이해도 달라질 필요성이 대두되었다(Stambler 2017). 지난 수십 년간 심리발달, 인지발달, 운동발달, 사회정서발달 등 다양한 분야의 전문가들이 발달 관련 연구 결과를 발표하였 다(Knight 2017). 발달이란 뇌, 신체, 환경 사이의 복합 체계 적 상호작용 결과이며, 매우 유동적이고 비선형(non-linear) 이라는 결론을 도출해 냈고, 그 결과 비선형 역동적 발달체 계이론(dynamic developmental systems theory)이 발달했 다. 특히 청소년기와 성인기 사이에 구조체계가 붕괴되고 재 조직화되는 과정이 반복되는 시기가 있음을 알게 되었으며, 이를 emerging adulthood로 명명하였다(Figure 1) (Arnett 2000). 현대 산업사회의 통계 및 인구학적 연구에서 emerging adulthood 출현의 이유로 성인으로서의 책임감이 이십 대 말로 이동하는 것을 들고 있다(Settersten과 Ray 2010). 직 업의식이 분명하지 않다 보니 직장을 그만두고 옮기기도 하 고 대학원에 진학하기도 한다. 실업 문제는 결혼 연령과 연 결된다(Shulman 2017). 또한 급변하는 사회 환경(디지털 소 통, 작업환경의 디지털화, 고용기회의 감소 등) 때문에 세대 간 격차도 커진다. 이러한 청소년기의 변화와 성인기 진입의 변화를 인식하지 못하면 오늘날 젊은 세대가 성인기 진입 시 직면한 문제들을 이해하기 어렵다(Shulman 2017). Arnett (2000)의 emerging adulthood는 '정신분석'에 한 차례 소개된 바 있으나(Bahn 등 2015), 당시 우리말 용어는 사용하지 않 았고 연구자에 따라 '성인이행기'(Lee 등 2020), '성인진입기' 
(Yi와 Yang 2020), '성인모색기'(Kim 2016), '신흥성인기' (Lee 등 2016), '신생성인기'(Park 2017) 등으로 각기 다르게 사용되고 있으므로, 본 연구에서는 영문으로 표기하였다.

Emerging adulthood 발달 변화에 영향을 미치는 요소는 환경, 문화배경, 개인의 심리 요인 등이며, 조절 기능을 하는 구조물과 체계가 매개역할을 한다(Knight 2017). 비선형 역 동적 발달체계이론에 따르면 미시적 수준(micro level)에서 의 개인차이는 물론, 거시적 수준(macro level)에서 직선적 및 비선형 발달을 이해함으로써 발달 문제에 봉착한 환자를 적절하게 도와줄 수 있다. 미시적 수준의 예를 보자. 분석가 는 피분석가의 무의식적 동일시, 의존성, 죄책감 등을 분석과 정을 통해 이해할 수 있도록 도와줌으로써, 피분석가가 자신 의 능력을 적절히 사용하고 나이에 맞게 발달한다(Chused 2017). 거시적 수준의 발달 예는 동작이 재빠르고 적극적 성 향의 아기와 동작이 느리고 차분한 성향의 아기가 장난감을 집을 수 있는 확률의 차이에서 알 수 있는 것처럼 명확하다 (Thelen과 Spencer 1988). 청소년기를 벗어나는 데 어려움이 있는 청소년의 경우 심리적 걸림돌을 제거하도록 도와주거 나, 다음 단계로 넘어가는 데 필요한 것을 지원해 주는 방법 을 찾는 것이다. 태어나서부터 노년기까지 몸과 두뇌가 계속 변하고 문화적 환경에 적응해가는 과정은 불균형의 연속일 수 밖에 없지만, 그 과정은 곧 정상발달이다(Knight 2017). 즉 발전이란 불균형을 유발할 수 밖에 없으며, 개인이 자신의 능 력과 외부 환경을 유연하고 건설적으로 활용해가는 과정이 다. Emerging adulthood 역시 이러한 비선형 발달 과정을 거 쳐서 다음 성인기로 진입해야 한다(Knight 2017). 역동적 발 달체계 이론을 사용해서 발달개념을 확립해나가면 치료자 가 소아청소년과 성인 환자를 치료하는 방식이 바뀔 것이다. 환자의 현재와 미래 발달의 유동성과 재조직화에 걸림돌이 되는 낡고 경직된 믿음과 상호작용의 패턴을 밀어내고 새로 운 이론과 상호작용을 포함한 기법을 적용할 수 있어야 한 다. 치료자(분석가)는 환자의 발달을 돕는 대상이 돼야 한다 (Miller 2013).

Emerging adulthood 연령층에 대한 정신분석 문헌과 치 료지도감독 분석자료를 검토한 논문에서 Miller(2013)는 이 연령층에서 발달 과정을 방해하는 요소로 우울, 불안, 자기 의식 느낌, 자기비난과 부적절감, 엄마로부터의 분리 어려움 을 들었다. 100 명의 이스라엘 청년을 추적한 연구에서도 비슷 한 결과를 발견할 수 있다(Shulman 2017). Emerging adulthood에는 개인이 가진 자원(유능함, 낮은 자기비난, 낮은 의 존감)이 있어야 이 시기를 개방적이고 융통성 있게 지낼 수 있다. 이러한 개인 자원 외 부모의 지지가 결합된다면 더욱 다양하고 어려운 성인기 조건을 극복하고 성공적으로 헤쳐
나갈 것이라고 하였다. 이는 Stambler의 논문(2017)에서 개 인의 유능감에 대한 부모의 지지는 호모 사피엔(homo sapien) 시대 개막 이래 모든 발달 단계에서 주요 도움원이 된다 고 시사한 것과 일치한다. 흥미로운 점은 어머니의 지지 외 에 유용한 아버지의 지지 여부가 개인의 낮은 유능감에도 불 구하고, 직장에서의 어려움 극복이나 만족할 만한 경력 달성 의 예측인자라는 것이다.

\section{결 론}

초창기 청소년기 발달이론의 핵심은 '질풍노도의 시기'였 으나, 점차 모든 청소년이 이러한 감정 경과를 거치는 것은 아닌 것으로 밝혀지고 있다. 생물학의 빠른 발전은 기존 정신 분석 이론을 검증하는 주요 수단이 될 수 있다. 전두엽-변연 계 회로의 발달 불균형은 감정에 치우치기 쉬운 청소년기 특 성의 결정 요인이며, 대인관계나 사회적응 면에서 남녀 차이 가 있을 수 있다. 성전환술을 포함한 성정체성 문제는 새롭 게 부각되고 있는 다루기 어렵고 예민한 주제이다. 디지털 문화가 빠르게 확산되면서 청소년기 특성은 빠르게 변화하 고 있으며, emerging adulthood 개념이 등장하였다. 임상현 장의 전문가들은 청소년과 그 가족을 돕기 위해 고전적 정신 분석 이론의 직선적, 단계별 발달이론 과정을 익히고, 비선 형 역동적 발달체계 이론 등 새로운 치료기법에도 눈을 돌 려야 한다. 청소년기는 단순히 아동기와 성인기의 중간이행 과정일 뿐 아니라, 정체성 확립과 분리 개별화를 위한 긴 준 비 단계로 진화하고 발달하며 달라지고 있다.

\section{Acknowledgments}

None

\section{Conflicts of Interest}

The author has no potential conflicts of interest to disclose.

\section{ORCID iD}

Geon Ho Bahn https://orcid.org/0000-0002-3550-0422

\section{REFERENCES}

Agana MG, Greydanus DE, Indyk JA, Calles JL Jr, Kushner J, Leibowitz S, et al. Caring for the transgender adolescent and young adult: current concepts of an evolving process in the 21st century. Dis Mon 2019;65:303-356.

American Psychiatric Association. Diagnostic and statistical manual of mental disorders, 5th ed. Arlington, VA: American Psychiatric Association;2013.

Arnett JJ. Emerging adulthood. A theory of development from the late teens through the twenties. Am Psychol 2000;55:469-480

Arnett JJ, Cravens HG. Stanley Hall's adolescence: a centennial reappraisal introduction. Hist Psychol 2006;9:165-171.

Bahn GH, Ryu JE, Lee YJ, Han J, Lee A, Hong M. When is the endpoint of the adolescence? Psychoanalysis 2015;26:3-17. 
Bahn GH, Sun JYH, Hwangbo R, Hong M, Park JC, Cho SW. Is sorting hat in Harry Potter identity identifier for adolescents? J Korean Acad Child Adolesc Psychiatry 2017;28:38-43.

Blos P. The second individuation process of adolescence. Psychoanal Study Child 1967;22:162-186.

Chused JF. Listening to the transition: adolescent to adult. Psychoanal Study Child 2017;70:63-73.

Colarusso CA. Child and adult development: a psychoanalytic introduction for clinicians. New York: Plenum Press;1992. p.91-106.

Erikson EH. Identity: youth and crisis. New York: WW Norton \& company;1968. p.128-135.

Freud A. Adolescence. Psychoanal Study Child 1958;13:255-278.

Gay P. Freud: a life for our time. New York: WW Norton \& Company; 1998.

Gilmore K. Gender identity disorder in a girl: insights from adoption. J Am Psychoanal Assoc 1995;43:39-59.

Hall GS. Adolescence: its psychology and its relations to physiology, anthropology, sociology, sex, crime, religion, and education. New York: D. Appleton and Company; 1904.

Hwangbo R, Chang H, Hong M, Cho S, Bahn GH. The diagnostic distribution of psychiatric disorders among the population under 19 years old: based on the national insurance data. J Korean Acad Child Adolesc Psychiatry 2016;27:139-145.

Jacobs TJ. Early adolescence and its consequences. J Infant Child Adolesc Psychother 2000;1:135-157.

Kemp HV. G. Stanley Hall and the Clark school of religious psychology. American Psychologist 1992;47:290-298.

Kim E. A study on the identity exploration in an area of love/sexuality of the Korean young women in their 20s. Journal of Korean Women's Studies 2016;32:149-184.

King DL, Delfabbro PH, Billlieux J, Potenza MN. Problematic online gaming and the COVID-19 pandemic. J Behav Addict 2020;9:184-186.

Király O, Potenza MN, Stein DJ, King DL, Hodgins DC, Saunders JB, et al. Preventing problematic internet use during the COVID-19 pandemic: consensus guidance. Compr Psychiatry 2020;100:152180.

Knight R. Emerging adulthood and nonlinear dynamic systems theory. Psychoanal Study Child 2017;70:74-81.

Laqueur T. Making sex: body and gender from the Greeks to Freud. Cambridge, MA: Harvard University Press; 1990.

Lee J, Park J, Kim H, Oh S, Kwon S. Typology of young Korean adults' relationships with their parents from an intergenerational solidarity lens. Fam Environ Res 2020;58:43-60.

Lee WW, Kim MC, Choi Y. Dynamics of subjective class identification and upward mobility consciousness in Korea: time trends and ageperiod-cohort effects. Korean J Sociology 2016;50:247-284.

Mestre-Bach G, Blycker GR, Potenza MN. Pornography use in the setting of the COVID-19 pandemic. J Behav Addict 2020;9:181-183.

Miller JM. Developmental psychoanalysis and developmental objects. Psychoanalytic Inquiry 2013;33:312-322.

Money J. Gendermaps: social constructionism, feminism, and sexosophical history. New York: Continuum;1995.
Money J, Ehrhardt AA. Man and woman, boy and girl: differentiation and dimorphism of gender identity from conception to maturity. Baltimore: Johns Hopkins University Press; 1972.

Moon DS, Bahn GH. The concept of synchronization in the process of separation-individuation between a parent and an adolescent. Psychoanalysis 2016;27:35-41.

Muuss RE. Puberty rites in primitive and modern societies. Adolescence 1970;5:109-128.

Nealy EC. Transgender children and youth: cultivating pride and joy with families in transition. New York: WW Norton \& Company;2017. p.289317.

Nye RA. How sex became gender. Psychoanal Hist 2010;12:195-209.

Offer D, Schonert-Reichl KA. Debunking the myths of adolescence: findings from recent research. J Am Acad Child Adolesc Psychiatry 1992;31:1003-1014.

Park HS. A narrative inquiry on the lived experience of Korean Christian emerging adults. Journal of Christian Education and Information Technology 2017;52:35-73.

Price-Feeney M, Green AE, Dorison S. Understanding the mental health of transgender and nonbinary youth. J Adolescent Health 2020;66:684-690.

Saleh FM, Grudzinskas A Jr, Judge A. Adolescent sexual behavior in the digital age; considerations for clinicians, legal professionals, and educators. Oxford: Oxford University Press;2014. p.62-85.

Settersten RA Jr, Ray B. What's going on with young people today? The long and twisting path to adulthood. Future Child 2010;20:19-41.

Settlage CF, Galenson E. Psychology of women: late adolescence and early adulthood. J Am Psychoanal Assoc 1976;24:631-645.

Shulman S. The emerging adulthood years: finding one's way in career and intimate love relationships. Psychoanalytic Study of the Child 2017;70:40-62.

Silvers JA, Insel C, Powers A, Franz P, Helion C, Martin RE, et al. vlPFC-vmPFC-amygdala interactions underlie age-related differences in cognitive regulation of emotion. Cereb Cortex 2017;27:35023514.

Stambler MJL. 100 years of adolescence and its prehistory from cave to computer. Psychoanal Study Child 2017;70:22-39.

Suchet M. Crossing over. Psychoanal Dialogues 2011;21:172-191.

Thelen E, Spencer JP. Postural control during reaching in young infants: a dynamic systems approach. Neurosci Biobehav Rev 1998;22:507514.

Tylim I. Revisiting adolescents' narcissism in the age of cyberspace. Psychoanal Study Child 2017;70:130-134.

White SH. Child study at Clark University: 1894-1904. J Hist Behav Sci 1990;26:131-150.

Yi S, Yang S. A study on college students' attitude toward gender sensitivity education for early childhood. Korean Journal of Human Ecology 2020;29:311-324

Young KS, Sandman CF, Craske MG. Positive and negative emotion regulation in adolescence: links to anxiety and depression. Brain Sci 2019;9;76. 